\title{
The Eastern Putaohua Oil Reservoir In The Pubei Oilfield Microfacies Research
}

\author{
WU Yujie ${ }^{1}$, JIANG Chenggang ${ }^{2}$, ZHANG Yunfeng ${ }^{1}$, YUAN Hongqi ${ }^{1}$ \\ ${ }^{1}$ Northeast Petroleum University, Daqing 163318, China \\ ${ }^{2}$ Geological brigade of the Seventh Oil Extraction Plant of Daqing Oilfield Company Limited, \\ Daqing 163517, China \\ ${ }^{3}$ Northeast Petroleum University of Daqing City, Heilongjiang province in China
}

Keywords: Putaohua oil reservoir; Shallow water delta; Sedimentary microfacies; Plane distribution; Sedimentary evolution.

\begin{abstract}
Based on core and logging data, starting from the type of rock, mudstone color, size and sedimentary structure feature, set up the grape Pubei oilfield Putaohua oil reservoir fine sequence stratigraphic framework, draw the sedimentary facies of Putaohua oil reservoir in each small layer, summarize the evolution rules of sedimentary facies. The results show that the research area is the fluvial controlled shallow water deltaic depositional system. The research area is mainly the delta front subfacies deposition, and the development of underwater distributary channel, underwater distributary channel, main sheet sand, lamina sheet sand, underwater distributary mud other 5 kinds of sedimentary microfacies. According to the different microfacies log facies characteristics, study the small layer of sedimentary microfacies distribution, summarize the characteristics of Putaohua oil reservoir sedimentary evolution of grape.
\end{abstract}

\section{Introduction}

The Pubei oilfield in the structure is located in southern Changyuan, Songliao Basin in Daqing Putaohua structure north, its northwest is connected Gaotaizi construction with syncline structure, its northeast is connected Pacific construction with syncline structure. Putaohua oil reservoir is located in the upper Cretaceous in Songliao basin the member of Yaojia formation, is one of the main oil layers in northern Songliao Basin, its main oil reservoir is PI oil layer group, its depth of burial is $800 \sim 1000 \mathrm{~m}$.

\section{Facies marker}

\subsection{Petrologic feature}

The Putaohua oil reservoir is developed mainly fine sandstone, siltstone, argillaceous siltstone, silty mudstone and mudstone, occasionally medium sandstone. the clay mineral is based on hudromica, and followed by kaolinite and a small number of montmorillonite. ${ }^{[4]}$

2.2 Sedimentary tectonic characteristics

The sedimentary tectonics reserved in the Putaohua stratum are very rich, the structure of main physical factors have cross bedding, oblique bedding, horizontal bedding, wavy bedding, scrunch of structure, scour of structure, boulder clay; the structure of chemical factors have tuberculosis, pyrite, calcareous clumps and so on; the structure of biological factors have plant stems, breeze, bioturbation, ostracod of fossils ${ }^{[5]}$.

\section{The characteristics and type of sedimentary microfacies}

According to the core analysis of the coring well, the analysis of logging information and test data, the Putaohua oil layer is the shallow water delta front subfacies sedimentation controlled by the northwest provenance. (Figure 2-1). 


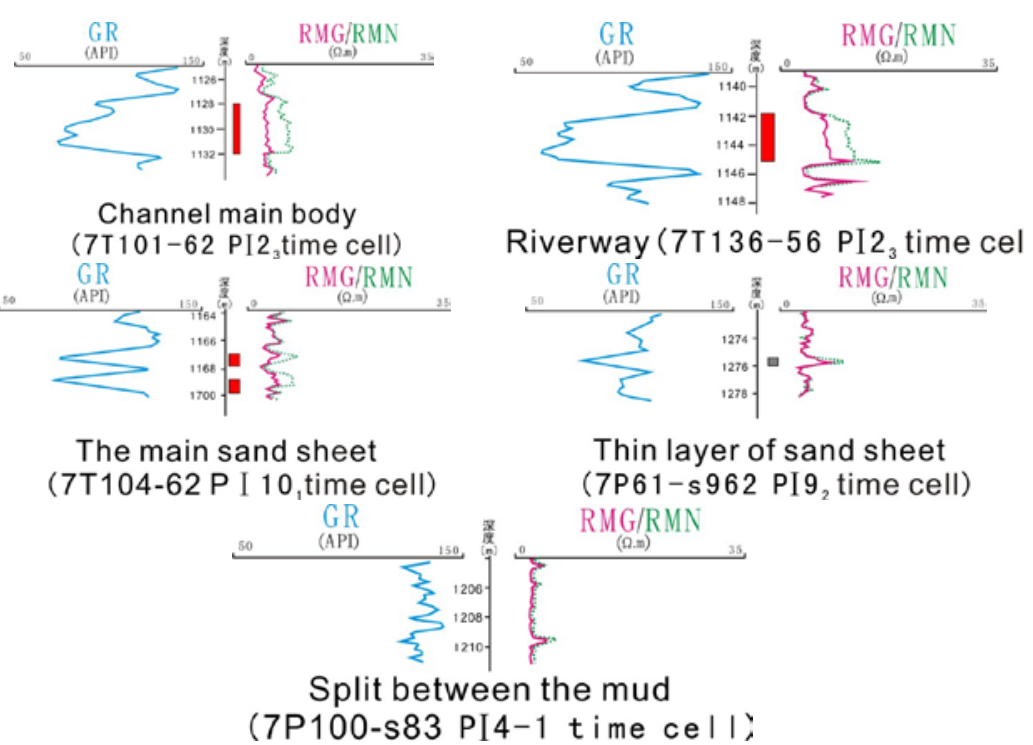

Figure2-1 Logging facies model in each microfacies of the Pubei oilfield Putaohua oil reservoir 3.1 The main microfacies of underwater distributary channel

The lithology of underwater distributary subject channel is mainly siltstone, sometimes mixed up with fine sandstone and argillaceous siltstone. It shows sedimentary characteristics of positive rhythm of discontinuity in the whole. It develops parallel bedding, cross bedding, oblique bedding bottom out, with minitype washing filling structure in the bottom, and the electrical logging shows the feature of medium to high range campaniform or box type.

3.2 The microfacies of underwater distributary channel

The underwater distributary channel is the continuation of delta plain distributary channel under the water. The lithology is main siltstone, followed by fine sandstone, argillaceous siltstone, silty mudstone and mudstone. It developed parallel bedding, oblique bedding, undulating compound bedding, with minitype washing filling structure in the bottom, and the electrical logging shows the feature of low to high range campaniform.

3.3 The subject sheet sand

Sheet sand is formatived rather thin and major area of sand body in the end, because of the underwater distributary channel transformed by the lake water scouring, sand body carried again, redistributed again. Sand body is generally interbedding between siltstone and mudstone. Its grade of maturity and compositional maturity of granule structure are rather high. It presents reverse rhythm or compound rhythm in vertical. The main sheet sand develop small cross bedding, ripple bedding. The electrical logging shows the finger state of medium range, and thickness of sand body is about $1 \sim 1.5 \mathrm{~m}$.

3.4 The lamina sheet sand

The lamina sheet sand is more argillaceous siltstone, is the rhythm of recombination, is developing minitype cross bedding, ripple bedding, and the electrical logging shows the finger state of medium range, and thickness of sand body is less than $1 \mathrm{~m}$.

3.5 The underwater distributary mud microfacies

Lithology of the underwater distributary mud microfacies is taking celadon and gray as the principal thing.The sedimentary tectonics are lenticular bedding, horizontal bedding and roiling structure. The electrical logging shows the feature of state of straight line or highly low range of tiny dentation.

\section{The planar distribution of sedimentary microfacies}

4.1 The planar distribution of sand body in the Putaohua oil reservoir 


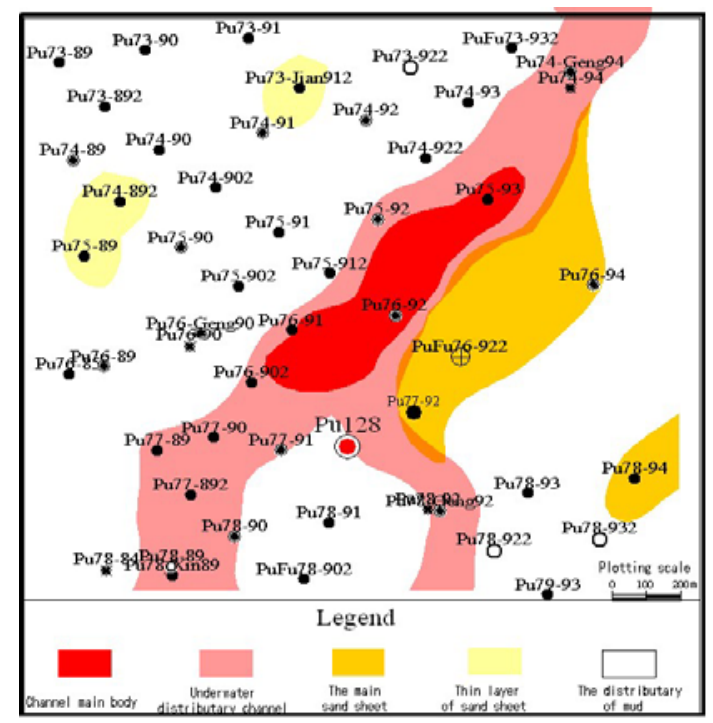

Figure 3-1 the sedimentary microfacies map of $\mathrm{PI}_{2}$ element in Pu 128 block Putaohua oil reservoir

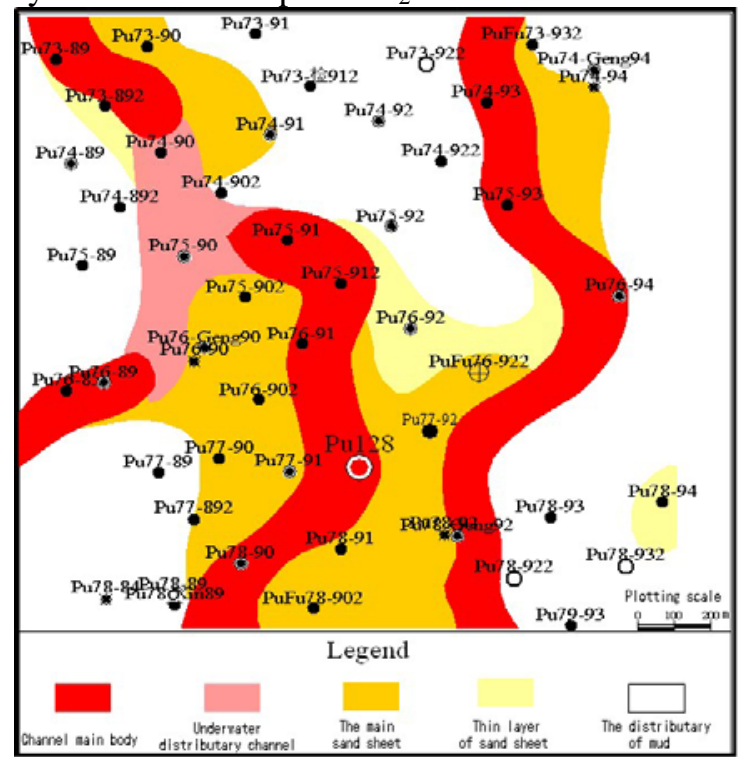

Figure 3-2 the sedimentary microfacies map of $\mathrm{PI}_{10} \mathrm{O}_{2}$ element in Pu 128 block Putaohua oil reservoir

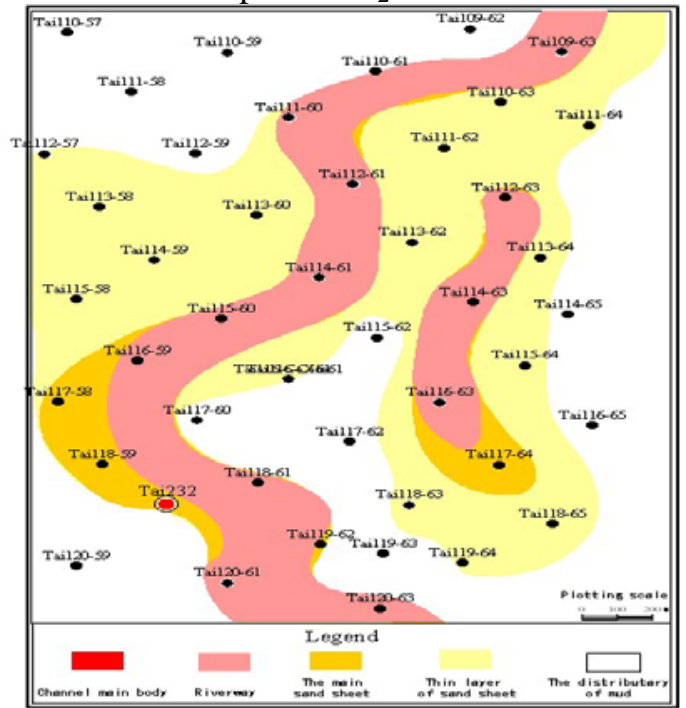

Figure 3-3 the sedimentary microfacies map of $\mathrm{PI}_{3}$ element in Tai 232 block Putaohua oil reservoir

The thickness of outer leading edge sand body is thin, and position is stabilization. It is continuous distribution in a large area in the plane, and the main developed subject is sheet sand and non main sheet sand, distributed widely in the PI1, $\mathrm{PI} 5_{3}, \mathrm{PI} 10_{3} \sim \mathrm{PI} 11_{3}$ time units. (Figure 3-1, Figure 3-2, Figure 3-3, Figure 3-4). 


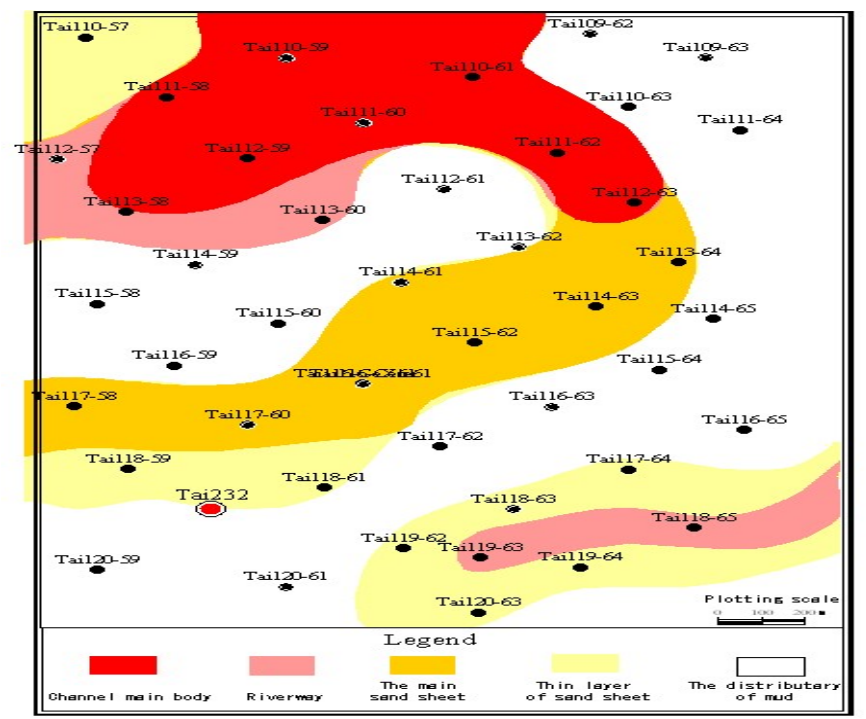

Figure 3-4 the sedimentary microfacies map of PI7 ${ }_{1}$ element in Tai 232 block Putaohua oil reservoir 4.2 The vertical evolution of the Putaohua oil reservoir

The P I group oil layer in the Pubei oilfield is taked shape in the background of the sedimentary environment of the lake surface declining, the lake surface stabilizing, the lake surface rising, and it has more level sedimentary cycles. In the overall context of water entering from bottom to top can be subdivided into outer leading edge of lake retreating type, transient phase of lake retreating type, within leading edge of lake retreating type, within leading edge of stable type, within leading edge of lake entering type, transient phase of lake entering type, and outer leading edge of lake entering type other 7 kinds of dispersed subfacies ${ }^{[6]}$.

\section{Conclusion}

(1) The reservoir of the Putaohua oil reservoir is developed mainly fine sandstone, siltstone, argillaceous siltstone, silty mudstone and mudstone, occasionally medium sandstone, and separation of rock is medium to good.

(2) The Pubei oilfield Putaohua oil reservoir is mainly the shallow water delta front subfacies sedimentation controlled by the northwest provenance.

(3) The Pubei oilfield Putaohua oil reservoir is formated shallow water deltaic depositional combination as the water entering background in general.

\section{Acknowledgements}

This work was financially supported by the Geological brigade of the Seventh Oil Extraction Plant of Daqing Oilfield Company Limited, Innovation Program of daqing Municipal Education Commission (060000) and daqing Leading Academic Discipline Project of daqing Municipal Education Commission.

\section{References}

[1] LIU Zongbao, YANG Tiejun, GONG Xun, LIU Hongtao. Tapping potential method and characteristics of remaining oil distribution of lithologic reservoir in block area-as Putaohua reservoir of Pubei oilfield in Songliao basin[J]. Journal of Northeast Petroleum University. 2013, 37(4): 32-38.

[2] LI Yu-ying, FU Xiao-fei, ZHANG Ming-xue. Fault Deformation Features and Reservoir-controlling Mechanisms of Xujiaweizi Fault Depression in Songliao Basin [J]. Natural Gas Geoscience. 2012(06): 979-988.

[3] Chu Tiantian, Pubei Oilfield T232 Wellblock Putaohua Reservoir Sedimentary 
Characteristics[D]. Northeast Petroleum University, 2014.

[4] SUN Yu, MA Shi-zhong, JIANG Hong-fu, LIU Zong-bao. Distribution characteristics ang controlling factors for reservoirs of Putaohua oil layer in Sanzhao Sag of Songliao Basin[J]. Journalof Central South University (Science and Technology). 2011(08): 2387-2393. 